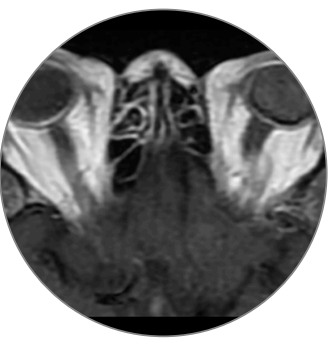

\section{Manifestaciones cerebrales y oculares del síndrome de Vogt-Koyanagi-Harada}

\author{
Vogt-Koyanagi-Harada Syndrome Cerebral and Ocular Manifestations
}

Luis Felipe Ovalle Daza

Catalina Wilches Vanegas ${ }^{2}$

\begin{abstract}
Resumen
El síndrome de Vogt-Koyanagi-Harada, antes conocido como síndrome uveomeningoencefálico, es una enfermedad rara, con muy pocos casos descritos en la literatura. Es una patología autoinmune infrecuente, con un compromiso multiorgánico. La resonancia magnética es importante para identificar las lesiones de la sustancia blanca periventricular, la afectación del tallo cerebral y los pedúnculos cerebrales, así como el realce paquimeníngeo y el engrosamiento difuso de la coroides. A pesar de ser una entidad poco frecuente, es importante que el radiólogo esté familiarizado con sus características en imágenes.
\end{abstract}

\title{
Summary
}

Vogt-Koyanagi-Harada syndrome, formerly kwon as uveomeningoencephalitic syndrome, is a rare disease, with very few cases reported in the literature. It is an uncommon autoimmune entity with multi-organ involvement. Magnetic resonance imaging is important to identify periventricular white matter lesions, brain stem and brain peduncles involvement, as well as pachymeningeal enhancement and diffuse choroidal thickening. Despite being a rare entity, it is important for the radiologist be acquainted with its imaging findings.

\section{Introducción}

El síndrome de Vogt-Koyanagi-Harada (SVKH) es un trastorno autoinmune multiorgánico infrecuente, con pocos casos descritos en la literatura moderna (1). El SVKH afecta principalmente el tejido pigmentado ocular, y causa alteraciones al tejido auditivo, tegumentario y al sistema nervioso central (SNC). Se caracteriza por uveítis bilateral, desprendimiento de retina, vitiligo, alopecia, hipoacusia, acúfenos, cefalea y meningismo (2). Las imágenes de resonancia magnética (RM) permiten identificar el compromiso de la coroides — con hallazgos típicos de engrosamiento difuso-, sin daño de la esclera, asociado a desprendimiento de la retina (3). Con respecto al SNC, los reportes iniciales describen lesiones alta señal en las secuencias potenciadas en T2 de la sustancia blanca periventricular, mientras que la literatura más reciente ha documentado lesiones en el tallo cerebral y los pedúnculos cerebrales, así como realce paquimeníngeo $(4,5)$. En el caso aquí expuesto se describen los hallazgos típicos, en RM cerebral, de una paciente con el SVKH.

\section{Caso clínico}

Paciente femenina de 63 años de edad con diagnóstico de SVKH, quien se presenta al Servicio de Radiología de la institución a la que pertenecen los autores, con uveítis, asociada a pérdida de la agudeza visual en el ojo izquierdo y disminución de la agudeza visual en el ojo derecho, además de zonas de despigmentación cutánea en los miembros superiores e inferiores detectadas al examen físico. La paciente refiere cefalea holocraneana ocasional e hipoacusia bilateral.

\section{Discusión}

El SVKH fue descrito inicialmente en el siglo X por el oftalmólogo bagdadí Ali Ibn Isa, quien reseñó el aspecto físico característico de inflamación ocular, despigmentación del pelo, cejas y pestañas. Se cree que una base genética puede ser un factor predisponente, ya que hay una mayor incidencia en los pacientes con piel más pigmentada; sin embargo, aún no se ha encontrado un patrón de herencia característico (2). Una de las teorías sugiere que el SVKH tiene manifestaciones clínicas variables, que dependen de la fase en la que se encuentre el síndrome en el momento de su presentación. La fisiopatología de esta enfermedad no se ha esclarecido completamente, pero se cree que está relacionada con una respuesta autoinmune causada por linfocitos $\mathrm{T}$, en contra de las proteínas tirosinasas relacionadas con los melanocitos, las cuales se encuentran en la úvea, la retina y en las leptomeninges (6).

El SVKH se desarrolla en cuatro fases: prodrómica, uveítis aguda, convalecencia y crónica recurrente. La fase prodrómica se presenta como una infección viral, y puede durar desde pocos días hasta algunas semanas. En esta fase las manifestaciones clínicas son principalmente extraoculares, como cefalea, meningismo, fiebre, náuseas, vértigo y alteraciones auditivas. 

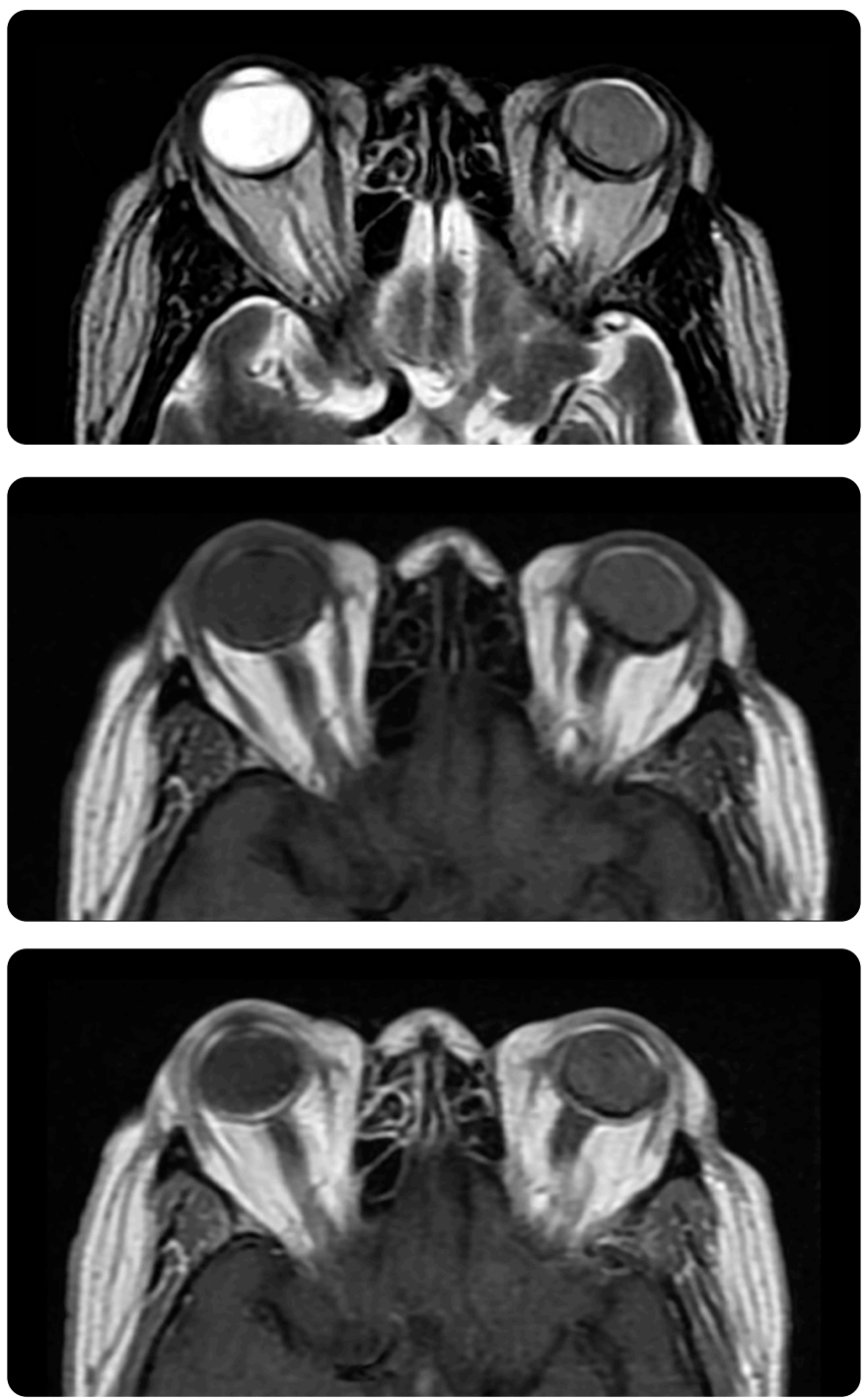

Figura 1. a) RM axial con información T2: engrosamiento coroideo bilateral; alteración en la morfología y en la señal del globo ocular izquierdo, disminución del tamaño, por cambios antiguos de desprendimiento de la retina izquierda y ausencia quirúrgica del cristalino. Faquectomía con lente intraocular en la órbita derecha. (b) RM con información T1 y c) con medio de contraste: engrosamiento y realce coroideo bilateral.

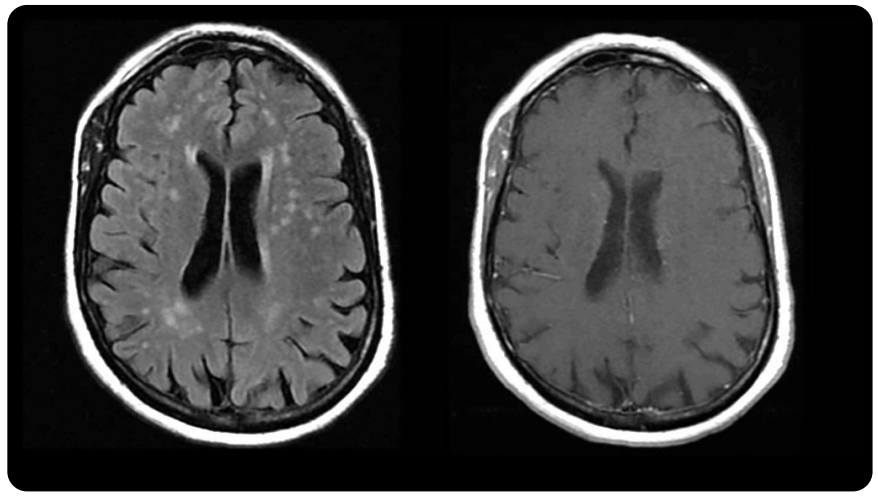

Figura 2. RM, axial FLAIR y eco de espín con información T1 y con medio de contraste: múltiples hiperintensidades en la sustancia blanca periventricular, centros semiovales y subcorticales bilaterales, estas lesiones no realzan con la administración del medio de contraste y pueden corresponder a cambios relacionados con la edad. No se observa realce paqui- ni leptomeníngeo.
La fase de uveítis aguda sigue a la prodrómica y en esta fase empieza la alteración súbita de la agudeza visual en ambos ojos, secundaria a una uveítis granulomatosa y engrosamiento de la coroides. La fase de convalecencia se presenta luego de varias semanas, o meses, después de la fase de uveítis aguda y puede durar varios meses. En esta fase se observa despigmentación de la coroides, vitiligo y poliosis. Por último, la fase crónica recurrente ocurre en algunos pacientes, se desarrolla entre 6 y 9 meses desde el inicio de los síntomas, y se caracteriza por exacerbaciones de la uveítis, la cual es resistente a la terapia con corticoesteroides sistémicos (7).

Aún no hay un consenso en el examen para el diagnóstico definitivo del SVKH, lo que lo limita a una combinación de estudios paraclínicos. El SVKH se clasifica en completo, incompleto y probable, con base en los siguientes criterios: 1 . Uveítis sin historia de trauma o cirugía ocular. 2. Uveítis sin evidencia clínica o paraclínica de otra enfermedad ocular. 3. Uveítis bilateral con desprendimiento de retina. 4. Compromiso auditivo o neurológico (no visual). 5. Hallazgos cutáneos (8). El SVKH completo cumple los 5 criterios. El SVKH incompleto cumple los 3 primeros criterios, con el criterio 4 o 5 . El SVKH se considera probable cuando el compromiso es ocular únicamente, solo cumpliendo los 3 primeros criterios (8). A pesar de ser una patología sistémica, hasta el $54 \%$ de los pacientes con el SVKH solo tienen síntomas oculares en la etapa temprana del síndrome. Teniendo en cuenta lo anterior, las manifestaciones extraoculares del SVKH completo pueden aparecer meses o años luego de las manifestaciones oculares iniciales (9).

Las imágenes de RM son una herramienta útil en el diagnóstico del SVKH; adicionalmente a los hallazgos oculares bilaterales (realce de la coroides en las imágenes con medio de contraste, con engrosamiento difuso, respeto de la esclera y desprendimiento de la retina) (figura 1), también se observan altas señales periventriculares difusas en las secuencias T2 y FLAIR (figura 2) (3). Además, recientemente se ha descrito el realce meníngeo como otro hallazgo de esta enfermedad en RM cerebral, pero no se encontró en el paciente de este caso (4). La habilidad de la RM en demostrar el realce meníngeo se ajusta a la teoría del compromiso de los tejidos ricos en melanocitos, y puede explicar los síntomas clínicos tempranos, como la cefalea que ocurre hasta en el $82 \%$ de los pacientes, antes del inicio de síntomas neurológicos francos, por lo que este realce puede ser un marcador temprano de la afectación del SNC (10).

\section{Conclusión}

El SVKH es una enfermedad autoinmune poco frecuente, que afecta múltiples órganos. La RM es útil para identificar el compromiso ocular y cerebral, por lo que es importante que el radiólogo esté familiarizado con sus características y los diferentes hallazgos en imágenes.

\section{Referencias}

1. Lohman BD, Gustafson CA, Mckinney AM, Sarikaya B, Silbert SC. MR imaging of Vogt-Koyanagi-Harada syndrome with leptomeningeal enhancement. AJNR. 2011;32(9):E169-71.

2. Moorthy RS, Inomata H, Rao NA. Vogt-Koyanagi-Harada syndrome. Surv Ophthalmol 1995;39(4): 265-92.

3. Ibanez HE, Grand MG, Meredith TA, Wippold FJ. Magnetic resonance imaging findings in Vogt-Koyanagi-Harada syndrome. Retina. 1994;14(2):164-8.

4. Han HJ, Kim HY, Park JH, Lee EJ, Kim Do G, et al. Magnetic resonance imaging of pachymeningeal enhancement in Vogt-Koyanagi-Harada disease. Neurol Sci. 2010;31(6):785-8.

5. Hashimoto T, Takizawa H, Yukimura K, Ohta K. Vogt-Koyanagi-Harada disease associated with brainstem encephalitis. J Clin Neurosci. 2009;16(4):593-5. 
6. Rao NA. Mechanisms of inflammatory response in sympathetic ophthalmia and VKH syndrome. Eye. 1997;11:213-6.

7. O'keefe GAD, Rao NA. Vogt-Koyanagi-Harada disease diagnostic criteria. Surv Ophthalmol. 2016;62(1):1-25.

8. Read RW, Holland GN, Rao NA, Tabbara KF, Ohno S, et al. Revised diagnostic criteria for Vogt-Koyanagi-Harada disease: report of an international committee on nomenclature. Am J Ophthalmol. 2001;131(5):647-52.

9. Rao NA, Gupta A, Dustin L, Chee SP, Okada AA, et al. Frequency of distinguishing clinical features in Vogt-Koyanagi-Harada disease. Ophthalmology. 2010;117(3):591-9.

10. Rao NA, Sukavatcharin S, Tsai JH. Vogt-Koyanagi-Harada disease diagnostic criteria. Int Ophthalmol. 2007;27(2-3):195-9.

\section{Correspondencia}

Luis Felipe Ovalle Daza

Carrera 17 \# 96-61, apto 501

Bogotá, Colombia

pipeovalle17@gmail.com

Recibido para evaluación: 30 de noviembre de 2020

Aceptado para publicación: 19 de enero de 2021 